\title{
Small for gestational age and obesity related comorbidities
}

Yong Hee Hong, MD, PhD', Sochung Chung, MD, PhD ${ }^{2}$

${ }^{1}$ Department of Pediatrics, Soonchunhyang University Bucheon Hospital, Soonchunhyang University School of Medicine, Bucheon, ${ }^{2}$ Department of Pediatrics, Konkuk University Medical Center, Konkuk University School of Medicine, Seoul, Korea

Received: 2 March, 2018

Accepted: 15 March, 2018

Address for correspondence:

Sochung Chung, MD, PhD

Department of Pediatrics, Konkuk University Medical Center, Konkuk University School of Medicine, 120-1 Neungdong-ro, Gwangjin-gu, Seoul 05030, Korea

Tel: +82-2-2030-7553

Fax: +82-2-2030-7748

E-mail: scchung@kuh.ac.kr

https://orcid.org/0000-0002-76552691
Infant born small for gestational age (SGA) are at increased risk of perinatal morbidity, persistent short stature and metabolic alterations in later life. The result of SGA followed by rapid weight gain during early postnatal life has been associated with increased long-term risks for central obesity, insulin resistance, impaired glucose tolerance, type 2 diabetes, hypertension, increased fat mass, and cardiovascular disease. We should carefully monitor their weight during infancy and childhood to prevent excessive rates of weight gain. 'Healthy catch up growth' may decreased the risk of obesity-related comorbidities in SGA. Establishing the optimal growth patterns in SGA to minimize short- and long-term risks is important, and further studies will be needed. This review discusses recent studies concentrating on obesity-related morbidities in SGA infants that may provide insight into growth monitoring.

Keywords: Obesity, Small for gestational age, Metabolic syndrome

\section{Introduction}

Childhood obesity is an increasingly important public health issue both worldwide and in Korea. One potential predictor of later obesity is birth weight. Both small for gestational age (SGA) and large for gestational age (LGA) are correlated with obesity and obesity related morbidities over the course of an individual's life. Those who are born SGA are at risk of developing metabolic disease later in life, particularly obesity, insulin resistance, glucose intolerance, cardiovascular disease, and dyslipidemia. ${ }^{1)}$ Approximately 85\% of SGA infants achieve appropriate catch-up growth, ${ }^{2)}$ and they tend to gain weight more rapidly during the early postnatal period. Catch-up growth and accelerated postnatal weight gain is associated with an increased risk of adiposity and metabolic disease later in life. ${ }^{3-5)}$ This review discusses recent studies concentrating on obesity related morbidities in SGA infants that may provide insight into growth monitoring.

\section{Obesity and SGA}

An association between birth weight and development of obesity has been reported in numerous publications. ${ }^{6-12)}$ High birth weight is most strongly associated with subsequent childhood obesity. ${ }^{6}$ SGA birth is also associated with greater adiposity (percentage body fat and fat mass), obesity, and particularly truncal obesity, in later childhood and adulthood. ${ }^{7.8}$ Some studies have suggested that SGA infants remain lighter and have less body fat and others found them to be more likely to exhibit obesity in childhood, in particular with catch-up growth. ${ }^{9-12)}$ Older studies published from the 1970 s to the 1990 s, before the obesity epidemic that began in the 1980s, reported long-term reductions in height, weight, body mass index (BMI), and skinfold thickness in SGA. ${ }^{12)}$ 


\section{Effects of fetal growth retardation timing in SGA}

Human development rates are highest during the first trimester of pregnancy. This period is essential for development of fetal cardiovascular and metabolic organs. ${ }^{13)}$ Smaller first trimester fetal crown to rump length was reported to be associated with higher total fat mass percentage, android/gynoid fat mass ratio, diastolic blood pressure, and total cholesterol concentration in childhood. ${ }^{14)}$ The observed associations suggest that the first trimester of pregnancy is a critical period for cardiovascular health in later life. One study documented that the exposure to famine in the first 2 trimesters of pregnancy is associated with increased obesity. ${ }^{15)}$ In contrast, those exposed to famine during the last trimester of pregnancy have reduced obesity rate. ${ }^{15)}$ The exact mechanisms for the associations of first trimester fetal growth and risk factors for cardiovascular disease remain unclear, but they may include changes in methylation of DNA and expression of RNA in response to a suboptimal fetal environment. ${ }^{16)}$

\section{Adiposity in SGA}

There are many reports showing an inverse association between birth weight and central fat deposition. ${ }^{7,17-20)}$ SGA infants have a continuously altered pattern of fat accumulation. ${ }^{21)}$ At birth, SGA infants included in the study had less adipose tissue than appropriate for gestational age (AGA) infants. Differences in anthropometric indices were continued until 6 weeks of age; however, adipose tissue distribution did not differ between AGA and SGA infants at that time. ${ }^{17)}$ When Harrington et al. ${ }^{18)}$ evaluated subcutaneous and intraabdominal fat distribution in SGA, in contrast to the highly significant differences in subcutaneous fat tissue between AGA and SGA infants, they detected no significant differences in intra-abdominal adipose tissue. SGA infants exhibit a tendency to transition toward central adiposity, which enhances insulin resistance. Yoshikawa et al. ${ }^{19)}$ reported that the sum thickness of four skinfolds (triceps, biceps, suprailiac, and subscapular) in SGA infants was thinner at birth and caught up to AGA infants within 1 month, which supported a rapid postnatal catch-up fat phenomenon in SGA infants. Even though children born SGA remain slightly smaller than AGA children, they also exhibit reduced lean tissue mass without a reduction in fat mass, and thus have a higher percentage of body fat. ${ }^{7)}$ Also in adolescents, SGA could be associated with a higher subcutaneous truncal fat distribution. ${ }^{20)}$

The mechanism of rapid postnatal fat accumulation in SGA infants has been investigated in some studies. ${ }^{19,22)}$ Some hormonal and metabolic factors may be related to early postnatal increases in fat accumulation. Lipoprotein lipase (LPL)-mediated lipolysis of very-low density lipoprotein (VLDL) and triglyceride (TG) may be one of the major mechanisms of rapid growth in subcutaneous fat tissue exhibited in SGA. ${ }^{19)}$ A rapid postnatal increase in LPL mediates
TG uptake from VLDLs. ${ }^{22)}$ A marked postnatal increase in insulin-like growth factor- 1 observed in SGA infants is one of the causes of rapid postnatal subcutaneous fat accumulation. ${ }^{19)}$

\section{Role of catch-up growth/fat and obesity-related comorbidities in SGA infants}

Catch-up growth refers to cross upwards by at least a onepercentile band on standard growth charts, equivalent to a gain in weight SD score of at least 0.67 . $^{4)}$ This catch-up growth may be advantageous for survival and may have long-term benefits with regard to cognitive development and stature. ${ }^{23)}$ However, catch-up growth and rapid postnatal weight gain has been reported to be associated with an increased risk of adiposity and metabolic disease later in life. Patterns in first-year weight gain seem to influence metabolic risk. ${ }^{24,25)}$ The effects of early, rapid weight gain are similar in non-SGA infants. ${ }^{26,27)}$ A study of young adults born AGA or SGA found that those who gained weight most rapidly (fast catch-up) during the first 3 months of life had the worst cardiovascular and metabolic risk profile. ${ }^{28)}$ This sequence of SGA followed by fast catch-up in the first few months, which is the cell division period, has been reported to be associated with increased long-term risk for central obesity, insulin resistance, type 2 diabetes and cardiovascular disease. ${ }^{29)}$

\section{SGA and metabolic syndrome}

The term metabolic syndrome refers to the presence of visceral obesity, dyslipidemia, impaired glucose tolerance or overt type 2 diabetes mellitus and hypertension as a cluster. ${ }^{30)}$ The fetal origins hypothesis suggests that SGA infants are at higher risk of developing metabolic syndrome later in adulthood. ${ }^{31)}$ There are conflicting data regarding the association between SGA and metabolic syndrome in children, adolescents and young adults. ${ }^{32-34)}$ In a study of Korean adolescents, there were no differences in metabolic syndrome components among those that were SGA and non-SGA at birth, possibly due to different eating habits or racial traits. ${ }^{34)}$

Low-birth-weight, but not catch-up growth, correlates with insulin resistance indices at 12 months, suggesting early occurrence of metabolic abnormalities ${ }^{35)}$ Early programming of insulin resistance plays a key role in the development of adult metabolic disease in those who are SGA at birth. ${ }^{36-38)}$ Insulin resistance or reduced insulin sensitivity may increase the risk of type 2 diabetes in adulthood, especially for SGA infants with catch-up growth and a high BMI. ${ }^{39)}$ Higher levels of insulin are closely correlated with postnatal height catch-up growth in young SGA children and with weight catch-up growth in older children. ${ }^{40)}$

SGA children with higher BMI were more insulin resistant than AGA children with similar weight and BMI. ${ }^{41)}$ Obese SGA children have higher fasting insulin, homeostatic model assessment-insulin resistance, glucose and insulin levels at 120 minutes after a glucose load compared with obese non-SGA 
children. ${ }^{42)}$ Overweight SGA children are also at increased risk of components of metabolic syndrome compared with overweight AGA children. ${ }^{43)}$ These findings suggest that metabolic alterations in SGA are caused by both adverse fetal programming and obesity. In a recent study, school-age children and adolescents with combined fetal growth restriction and prematurity (preterm SGA) exhibited an increased prevalence of glucose risk and metabolic syndrome compared with term SGA or preterm AGA. ${ }^{44)}$ This indicates that prematurity alone does not impact metabolic risk, while suggesting the influence of being born SGA. ${ }^{44)}$

Evidence regarding lipid outcomes has been inconsistent. ${ }^{45)}$ A meta-analysis showed a small but significantly inverse association between total cholesterol and birth weight. ${ }^{46)}$ De Jong et al. ${ }^{47)}$ reported a high prevalence of high triglyceride levels at 1 year of age in SGA children compared to AGA children. However, unlike insulin resistance, total cholesterol and lowdensity lipoprotein cholesterol levels were not significantly different between obese SGA and obese non-SGA children. ${ }^{42}$ Most studies reported no association between postnatal growth and lipid levels. ${ }^{45)}$

\section{Cardiovascular disease in obese SGA}

The relationship between birth weight and coronary artery disease has been demonstrated in many studies. ${ }^{9,48-58)}$ Prenatal growth restriction can result in prenatal circulatory adaptations and altered heart and vascular tree development. ${ }^{48)}$ Furthermore, hypertension in adult may be caused by a reduction in nephrons, decreased synthesis of elastin in the walls of the aorta, and large arteries due to fetal malnutrition. ${ }^{49,50)}$ Low birth weight has a tendency to cause high adult blood pressure. ${ }^{51,52)}$ However, cardiovascular disease risk in SGA children was not yet observed in blood pressure and laboratory measurements at age 6-12 years. ${ }^{9)}$

Leunissen et al. ${ }^{53)}$ reported no associations between weight at birth and blood pressure at 21 years, but found positive association between weight gain and intima media thickness of the common carotid artery in young adults. This indicates that childhood weight gain, especially fat mass, rather than SGA itself has a greater influence on young adult blood pressure. ${ }^{53)}$ There is a stronger association between low birth weight and the risk of coronary heart disease among men with high BMI at adolescence, compared with men with low BMI. ${ }^{54)}$ This suggests that weight gain in adolescence may influence the relationship between birth weight and coronary heart disease. ${ }^{54)}$ Intima media thickness of the common carotid artery, which is a wellknown marker of subclinical atherosclerosis, was significantly increased in obese children born SGA compared with obese children born AGA of a similar age, sex and BMI. ${ }^{55)}$

\section{Healthy catch-up growth in SGA infants}

As we reviewed above, rapid catch-up growth after birth in
SGA infants is related to a number of obesity related metabolic disorders. Persistent poor postnatal growth is associated with more frequent infection, short stature and impaired cognitive development in SGA. ${ }^{56)}$ Lei et al. ${ }^{57)}$ suggested that the optimal growth trajectory for SGA may be fast catch-up growth to about the 30th percentile in the first several months, with modest catch-up growth thereafter, to around the 50th percentile by 7 years old. Establishing the optimal growth patterns in SGA to minimize short- and long-term risks is important, and further studies will be needed. For healthy catch-up growth, nutrition guidelines and growth targets are also needed to balance associated risks.

\section{Conclusions}

The higher probability of SGA infants developing metabolic alterations could be related to both increased weight gain (catch-up growth) and fetal programming. ${ }^{58)}$ Even with the same high BMI status, obese SGA individuals have more severe morbidities compared with obese non-SGA individuals. Gains in body fat mass, especially central fat might be predict adverse metabolic outcomes. Birth weight is an endpoint of different fetal exposures and growth patterns and the starting point of childhood growth. To prevent metabolic syndrome and cardiovascular disease, early interventions for obesity and routine monitoring of healthy growth is important in those born SGA. It may be necessary to evaluate metabolic parameters in overweight or obese SGA children.

\section{Conflict of interest}

No potential conflict of interest relevant to this article was reported.

\section{References}

1. Varvarigou AA. Intrauterine growth restriction as a potential risk factor for disease onset in adulthood. J Pediatr Endocrinol Metab 2010;23:215-24.

2. Karlberg J, Albertsson-Wikland K. Growth in full-term small-for-gestational-age infants: from birth to final height. Pediatr Res 1995;38:733-9.

3. Eriksson JG, Forsén T, Tuomilehto J, Osmond C, Barker DJ. Early growth and coronary heart disease in later life: longitudinal study. BMJ 2001;322:949-53.

4. Ong KK, Ahmed ML, Emmett PM, Preece MA, Dunger DB. Association between postnatal catch-up growth and obesity in childhood: prospective cohort study. BMJ 2000;320:96771.

5. Woo Baidal JA, Locks LM, Cheng ER, Blake-Lamb TL, Perkins ME, Taveras EM. Risk factors for childhood obesity in the first 1,000 days: a systematic review. Am J Prev Med 2016;50:761-79.

6. Gillman MW, Rifas-Shiman S, Berkey CS, Field AE, Colditz 
GA. Maternal gestational diabetes, birth weight, and adolescent obesity. Pediatrics 2003;111:e221-6.

7. Hediger ML, Overpeck MD, Kuczmarski RJ, McGlynn A, Maurer KR, Davis WW. Muscularity and fatness of infants and young children born small- or large-for-gestationalage. Pediatrics 1998;102:E60.

8. Biosca M, Rodríguez G, Ventura P, Samper MP, Labayen I, Collado MP, et al. Central adiposity in children born small and large for gestational age. Nutr Hosp 2011;26:971-6.

9. Kuhle S, Maguire B, Ata N, MacInnis N, Dodds L. Birth weight for gestational age, anthropometric measures, and cardiovascular disease markers in children. J Pediatr 2017;182:99-106.

10. Gallo P, Cioffi L, Limauro R, Farris E, Bianco V, Sassi R, et al. SGA children in pediatric primary care: What is the best choice, large or small? A 10-year prospective longitudinal study. Glob Pediatr Health 2016;3:2333794x16659993.

11. Yu ZB, Han SP, Zhu GZ, Zhu C, Wang XJ, Cao XG, et al. Birth weight and subsequent risk of obesity: a systematic review and meta-analysis. Obes Rev 2011;12:525-42.

12. Kramer MS, Martin RM, Bogdanovich N, Vilchuk K, Dahhou M, Oken E. Is restricted fetal growth associated with later adiposity? Observational analysis of a randomized trial. Am J Clin Nutr 2014;100:176-81.

13. Robinson HP. Sonar measurement of fetal crown-rump length as means of assessing maturity in first trimester of pregnancy. Br Med J 1973;4:28-31.

14. Jaddoe VW, de Jonge LL, Hofman A, Franco OH, Steegers EA, Gaillard R. First trimester fetal growth restriction and cardiovascular risk factors in school age children: population based cohort study. Bmj 2014;348:g14.

15. Ravelli GP, Stein ZA, Susser MW. Obesity in young men after famine exposure in utero and early infancy. N Engl J Med 1976;295:349-53.

16. Gluckman PD, Hanson MA, Cooper C, Thornburg KL. Effect of in utero and early-life conditions on adult health and disease. N Engl J Med 2008;359:61-73.

17. Modi N, Thomas EL, Harrington TA, Uthaya S, Doré CJ, Bell JD. Determinants of adiposity during preweaning postnatal growth in appropriately grown and growthrestricted term infants. Pediatr Res 2006;60:345-8.

18. Harrington TA, Thomas EL, Frost G, Modi N, Bell JD. Distribution of adipose tissue in the newborn. Pediatr Res 2004;55:437-41

19. Yoshikawa K, Okada T, Munakata S, Okahashi A, Yonezawa $\mathrm{R}$, Makimoto M, et al. Association between serum lipoprotein lipase mass concentration and subcutaneous fat accumulation during neonatal period. Eur J Clin Nutr 2010;64:447-53.

20. Labayen I, Moreno LA, Ruiz JR, González-Gross M, Wärnberg J, Breidenassel C, et al. Small birth weight and later body composition and fat distribution in adolescents: the Avena study. Obesity (Silver Spring) 2008;16:1680-6.

21. Ratnasingham A, Eiby YA, Dekker Nitert M, Donovan T, Lingwood BE. Review: is rapid fat accumulation in early life associated with adverse later health outcomes? Placenta
2017;54:125-30.

22. Okada T, Takahashi S, Nagano N, Yoshikawa K, Usukura Y, Hosono S. Early postnatal alteration of body composition in preterm and small-for-gestational-age infants: implications of catch-up fat. Pediatr Res 2015;77:136-42.

23. Yeung MY. Postnatal growth, neurodevelopment and altered adiposity after preterm birth--from a clinical nutrition perspective. Acta Paediatr 2006;95:909-17.

24. Mericq V, Martinez-Aguayo A, Uauy R, Iñiguez G, Van der Steen M, Hokken-Koelega A. Long-term metabolic risk among children born premature or small for gestational age. Nat Rev Endocrinol 2017;13:50-62.

25. Zheng M, Lamb KE, Grimes C, Laws R, Bolton K, Ong KK, et al. Rapid weight gain during infancy and subsequent adiposity: a systematic review and meta-analysis of evidence. Obes Rev 2018;19:321-32.

26. Ong KK. Catch-up growth in small for gestational age babies: good or bad? Curr Opin Endocrinol Diabetes Obes 2007;14:30-4.

27. Chomtho S, Wells JC, Williams JE, Davies PS, Lucas A, Fewtrell MS. Infant growth and later body composition: evidence from the 4-component model. Am J Clin Nutr 2008;87:1776-84.

28. Leunissen RW, Kerkhof GF, Stijnen T, Hokken-Koelega A. Timing and tempo of first-year rapid growth in relation to cardiovascular and metabolic risk profile in early adulthood. JAMA 2009;301:2234-42.

29. Ibáñez L, Ong K, Dunger DB, de Zegher F. Early development of adiposity and insulin resistance after catchup weight gain in small-for-gestational-age children. J Clin Endocrinol Metab 2006;91:2153-8.

30. Alberti KG, Zimmet P, Shaw J. The metabolic syndrome: a new worldwide definition. Lancet 2005;366:1059-62.

31. Hales CN, Barker DJ. Type 2 (non-insulin-dependent) diabetes mellitus: the thrifty phenotype hypothesis. Diabetologia 1992;35:595-601.

32. Hirschler V, Bugna J, Roque M, Gilligan T, Gonzalez C. Does low birth weight predict obesity/overweight and metabolic syndrome in elementary school children? Arch Med Res 2008;39:796-802

33. Ramadhani MK, Grobbee DE, Bots ML, Castro Cabezas M, Vos LE, Oren A, et al. Lower birth weight predicts metabolic syndrome in young adults: the Atherosclerosis Risk in Young Adults (ARYA)-study. Atherosclerosis 2006; 184:217.

34. Cho WK, Jung IA, Suh BK. Current growth status and metabolic parameters of Korean adolescents born small for gestational age: results from the Korea National Health and Nutrition Examination Surveys (KNHANES) 2010-2011. Pediatr Int 2014;56:344-8.

35. Giapros V, Vavva E, Siomou E, Kolios G, Tsabouri S, Cholevas V, et al. Low-birth-weight, but not catch-up growth, correlates with insulin resistance and resistin level in SGA infants at 12 months. J Matern Fetal Neonatal Med 2017;30:1771-6

36. Norris SA, Osmond C, Gigante D, Kuzawa CW, 
Ramakrishnan L, Lee NR, et al. Size at birth, weight gain in infancy and childhood, and adult diabetes risk in five lowor middle-income country birth cohorts. Diabetes Care 2012;35:72-9.

37. Zhang Z, Kris-Etherton PM, Hartman TJ. Birth weight and risk factors for cardiovascular disease and type 2 diabetes in US children and adolescents: 10 year results from NHANES. Matern Child Health J 2014;18:1423-32.

38. Mericq V, Ong KK, Bazaes R, Peña V, Avila A, Salazar T, et al. Longitudinal changes in insulin sensitivity and secretion from birth to age three years in small- and appropriate-forgestational-age children. Diabetologia 2005;48:2609-14.

39. Veening MA, Van Weissenbruch MM, Delemarre-Van De Waal HA. Glucose tolerance, insulin sensitivity, and insulin secretion in children born small for gestational age. J Clin Endocrinol Metab 2002;87:4657-61.

40. Deng HZ, Li YH, Su Z, Ma HM, Huang YF, Chen HS, et al. Association between height and weight catch-up growth with insulin resistance in pre-pubertal Chinese children born small for gestational age at two different ages. Eur J Pediatr 2011;170:75-80.

41. Deng HZ, Deng H, Su Z, Li YH, Ma HM, Chen HS, et al. Insulin resistance and adiponectin levels are associated with height catch-up growth in pre-pubertal Chinese individuals born small for gestational age. Nutr Metab (Lond) 2012;9:107.

42. Dominguez Hernandez C, Klünder Klünder M, Huang F, Flores Armas EM, Velázquez-López L, Medina-Bravo P. Association between abdominal fat distribution, adipocytokines and metabolic alterations in obese lowbirth-weight children. Pediatr Obes 2016;11:285-91.

43. Reinehr T, Kleber M, Toschke AM. Small for gestational age status is associated with metabolic syndrome in overweight children. Eur J Endocrinol 2009;160:579-84.

44. Ramírez-Vélez R, Correa-Bautista JE, Villa-González E, Martínez-Torres J, Hackney AC, García-Hermoso A. Effects of preterm birth and fetal growth retardation on lifecourse cardiovascular risk factors among schoolchildren from Colombia: The FUPRECOL study. Early Hum Dev 2017;106-107:53-8.

45. Castanys-Muñoz E, Kennedy K, Castañeda-Gutiérrez E, Forsyth S, Godfrey KM, Koletzko B, et al. Systematic review indicates postnatal growth in term infants born small-forgestational-age being associated with later neurocognitive and metabolic outcomes. Acta Paediatr 2017;106:1230-8.

46. Owen CG, Whincup PH, Odoki K, Gilg JA, Cook DG. Birth weight and blood cholesterol level: a study in adolescents and systematic review. Pediatrics 2003;111(5 Pt 1):1081-9.
47. de Jong M, Cranendonk A, van Weissenbruch MM. Components of the metabolic syndrome in early childhood in very-low-birth-weight infants and term small and appropriate for gestational age infants. Pediatr Res 2015;78:457-61.

48. Cohen E, Wong FY, Horne RS, Yiallourou SR. Intrauterine growth restriction: impact on cardiovascular development and function throughout infancy. Pediatr Res 2016;79:82130 .

49. Zandi-Nejad K, Luyckx VA, Brenner BM. Adult hypertension and kidney disease: the role of fetal programming. Hypertension 2006;47:502-8.

50. Martyn CN, Greenwald SE. Impaired synthesis of elastin in walls of aorta and large conduit arteries during early development as an initiating event in pathogenesis of systemic hypertension. Lancet 1997;350:953-5.

51. Chen W, Srinivasan SR, Berenson GS. Amplification of the association between birthweight and blood pressure with age: the Bogalusa Heart Study. J Hypertens 2010;28:204652.

52. Ediriweera DS, Dilina N, Perera U, Flores F, Samita S. Risk of low birth weight on adulthood hypertension: evidence from a tertiary care hospital in a South Asian country, Sri Lanka: a retrospective cohort study. BMC Public Health 2017;17:358.

53. Leunissen RW, Kerkhof GF, Stijnen T, Hokken-Koelega AC. Effect of birth size and catch-up growth on adult blood pressure and carotid intima-media thickness. Horm Res Paediatr 2012;77:394-401.

54. Osler M, Lund R, Kriegbaum M, Andersen AM. The influence of birth weight and body mass in early adulthood on early coronary heart disease risk among Danish men born in 1953. Eur J Epidemiol 2009;24:57-61.

55. Stroescu R, Micle I, Marginean O, Bizerea T, Marazan M, Puiu M, et al. Is small for gestational age status associated with an increased risk of atherogenesis? Maedica (Buchar) 2013;8:315-20.

56. Saenger P, Czernichow P, Hughes I, Reiter EO. Small for gestational age: short stature and beyond. Endocr Rev 2007;28:219-51.

57. Lei X, Chen Y, Ye J, Ouyang F, Jiang F, Zhang J. The optimal postnatal growth trajectory for term small for gestational age babies: a prospective cohort study. J Pediatr 2015;166:54-8.

58. Matta J, Carette C, Levy Marchal C, Bertrand J, Pétéra M, Zins $\mathrm{M}$, et al. Weight for gestational age and metabolically healthy obesity in adults from the Haguenau cohort. BMJ Open 2016;6:e011367. 